\title{
IDENTIFICATION OF NEW SSR MARKERS LINKED TO LEAF CHLOROPHYLL CONTENT, FLAG LEAF SENESCENCE AND CELL MEMBRANE STABILITY TRAITS IN WHEAT UNDER WATER STRESSED CONDITION
}

\author{
Mohamed N. Barakat, ${ }^{1,2 *}$ Mohamed Saleh, ${ }^{3}$ Abdullah A. Al-Doss, ${ }^{1}$ \\ Khaled A. Moustafa, ${ }^{1}$ Adel A. Elshafei ${ }^{1,4}$ and Fahed H. Al-QurainY ${ }^{3}$ \\ 1Plant Production Department, College of Food and Agriculture Sciences, \\ King Saud University, Riyadh, Saudi Arabia \\ ${ }^{2}$ Biotechnology Laboratory, Crop Science Department, Faculty of Agriculture, \\ University of Alexandria, Alexandria, Egypt \\ 3Botany and Microbiology Department, College of Pure Science, King Saud University, \\ Riyadh, Saudi Arabia \\ ${ }^{4}$ Genetics and Cytology Department, Genetic Engineering and Biotechnology Division, \\ National Research Centre, El-Dokki, Cairo, Egypt
}

(Received: May 5, 2014; accepted: June 30, 2014)

\begin{abstract}
Segregating $\mathrm{F}_{4}$ families from the cross between drought sensitive (Yecora Rojo) and drought tolerant (Pavon 76) genotypes were made to identify SSR markers linked to leaf chlorophyll content, flag leaf senescence and cell membrane stability traits in wheat (Triticum aestivum L.) under water-stressed condition and to map quantitative trait locus (QTL) for the three physiological traits. The parents and $150 \mathrm{~F}_{4}$ families were evaluated phenotypically for drought tolerance using two irrigation treatments (2500 and $7500 \mathrm{~m}^{3} / \mathrm{ha}$ ). Using $400 \mathrm{SSR}$ primers tested for polymorphism in testing parental and $\mathrm{F}_{4}$ families genotypes, the results revealed that QTL for leaf chlorophyll content, flag leaf senescence and cell membrane stability traits were associated with 12, 5 and 12 SSR markers, respectively and explained phenotypic variation ranged from 6 to $42 \%$. The SSR markers for physiological traits had genetic distances ranged from 12.5 to $25.5 \mathrm{cM}$. These SSR markers can be further used in breeding programs for drought tolerance in wheat.
\end{abstract}

Keywords: Physiological traits - QTL - SSR markers - Triticum aestivum

\section{INTRODUCTION}

Drought is a major abiotic stress that affects wheat (Triticum aestivum L.) production in many regions of the world, limiting crop production in arid and semi-arid areas. Drought tolerance is a quantitative trait with complex phenotype and genetic control [16]. Therefore, understanding the genetic and physiological bases of drought tolerance in crop plants are a prerequisite for developing superior genotypes through plant breeding programs. In addition, selection for field performance is based on the selection for physiological traits related to drought tolerance. Among the physiological

\footnotetext{
*Corresponding author; e-mail address: mnrbarakat@yahoo.com
} 
traits that are associated with wheat performance under drought stresses, chlorophyll content $[14,26]$; flag leaf senescence $[3,30]$ and cell membrane stability [5] have been recognized as considerable indicators for drought tolerance in cereal crops. Maintaining a high yield in drought conditions has, therefore, become a priority, particularly when considering global environmental changes and the increase in world population [28]. Recently, identification of new TRAP and SRAP markers linked to chlorophyll content, leaf senescence and cell membrane stability in water-stressed wheat have been reported [11, 24]. However, the physiological basis of yield maintenance under drought conditions remained poorly understood [29]. Therefore, application of quantitative trait loci (QTLs) analysis to study the physiological traits will improve our understanding of genetic factors that influence these complex traits.

The molecular markers provide tools to study quantitative traits such as drought tolerance through quantitative trait loci (QTLs) analysis and are crucial in projects aiming to increase selection efficiency. Marker-assisted selection in improving drought responses in wheat was reported a few years ago [21]. In recent years, some QTLs for physiological traits under drought stress have been detected in cereal crops $[4,8,13]$. Marker assisted selection may reduce problems associated with genotype $\mathrm{X}$ environment interactions, improve the selection efficiency and facilitate combining different tolerance traits into a single genotype [29].

The objective of this investigation was to identify SSR markers linked to the chlorophyll content, leaf senescence, and cell membrane stability traits in wheat under water-stressed conditions and to identify QTLs for the chlorophyll content, leaf senescence, and cell membrane stability traits in $\mathrm{F}_{4}$ families using bulked segregant analysis.

\section{MATERIALS AND METHODS}

\section{Plant materials}

A set of 150 recombinant wheat (Triticum aestivum L.) inbred lines (RILs, at $\mathrm{F}_{4}$ ) developed from the cross between Pavon76 (drought tolerant cultivar introduced from CIMMYT) and Yecora Rojo (drought sensitive cultivar developed in USA and recommended for environment of Saudi Arabia since 1981) was used in this study. Yecora Rojo is a high yield, 2-gene dwarf cultivar but is very sensitive to environmental factors, such as drought stress, especially during the grain filling period [2]. The 150 recombinant inbred lines and the parents were tested for tolerance to drought under field condition. The water regimes were established after germination on the basis of free-surface evaporation monitored at a weather station located at the Agricultural Research Station of King Saud University (Dierab, near Riyadh; $24^{\circ} 42 \mathrm{~N}, 44^{\circ} 46 \mathrm{E}, 400 \mathrm{~m}$ above sea level). Two irrigation regimes [0.25 and 0.75 $\mathrm{m}^{3}\left(\mathrm{H}_{2} \mathrm{O}\right) \mathrm{m}^{-2}$ (soil)] were applied two weeks after sowing. The experiment was laid out in split-plot design with three replications. Water treatments were assigned to the main plots while the wheat genotypes distributed randomly over the sub-plots. 


\section{Measurement of physiological traits}

\section{Leaf chlorophyll content}

Leaf chlorophyll content was determined at the heading stage using a chlorophyll meter (SPAD-502, Konica sensing, INC., Japan) [20], using six flag leaves for each RILs and parents in well-watered and drought-stress conditions.

\section{Flag leaf senescence}

Leaf chlorophyll content representing the degree of leaf senescence in wheat was measured using chlorophyll meter (SPAD-502, Konica sensing, INC., Japan). Six flag-leaves for each RILs and parents were selected to evaluate the flag leaf chlorophyll content at heading (FCH). 35 days after heading, the same flag leaves were used to determine the chlorophyll content at maturity (FCM). The reduction speed of flagleaf chlorophyll content (RFC) as indicator for flag leaf senescence was calculated as described by Dwyer et al. [10]: RFC $=(F C H-F C M) / 35$.

\section{Cell membrane stability}

Medium part of flag leaves (three plants/replicate) was collected from field plots. Samples collected ( $2 \mathrm{~cm}$ segments) were washed three times in deionized water to remove electrolytes adhered on the surface according to the protocol of Blum and Ebercon [5]. The samples were then kept in a capped vial $(20 \mathrm{ml})$ containing $10 \mathrm{ml}$ of deionized water and incubated in the dark for $24 \mathrm{~h}$ at room temperature. The conductance was measured with a conductivity meter (HQ14d, Portable Meter, HACH Company, USA). After the first measurement the vials were autoclaved for $15 \mathrm{~min}$ to kill the leaf tissue and release the electrolytes. After cooling, the second conductivity reading was taken. These two measurements were carried out individually for all the samples from both the control and stress treatments. CMS was calculated as the reciprocal of cell-membrane injury following Blum and Ebercon [5]:

$$
\text { CMS\% }=\left[\left(1-\left(\mathrm{T}_{1} / \mathrm{T}_{2}\right)\right) /\left(1-\left(\mathrm{C}_{1} / \mathrm{C}_{2}\right)\right)\right]^{\prime} 100,
$$

where $\mathrm{T}$ and $\mathrm{C}$ refer to the stress and control samples, respectively; the subscripts 1 and 2 refer to the initial and final conductance readings, respectively.

\section{DNA extraction}

Frozen young leaves (500 mg) of 150 recombinant inbred lines (RILs, at F4) and their parents were individually ground to a powder in a mortar with liquid nitrogen. The DNA extraction was done using the CTAB method [23]. 


\section{PCR amplification}

400 SSR primers $[15,22]$ were used in this study. PCR amplication for SSR were carried out in a $20 \mu \mathrm{l}$ reaction mixture containing $1 \mathrm{X}$ buffer, $1.5 \mathrm{mM} \mathrm{MgCl} 2,0.1 \mathrm{mM}$ dNTPs, $500 \mathrm{nM}$ primer, $1 \mathrm{U}$ Taq polymerase, and 50-60 ng template DNA. The program of PCR cycle for SSR analysis included an initial denaturation at $94{ }^{\circ} \mathrm{C}$ for 3 min followed by 35 cycles of denaturation at $94^{\circ} \mathrm{C}$ for $1 \mathrm{~min}$; annealing at 50,55 or $60^{\circ} \mathrm{C}$ (depending on the individual microsatellite primer) for $1 \mathrm{~min}$; and extension at $72{ }^{\circ} \mathrm{C}$ for $2 \mathrm{~min}$ followed by a 17 -min final extension at $72{ }^{\circ} \mathrm{C}$. The amplification products have been electrophoresed in $2-3 \%$ agarose gels.

\section{Bulked segregant analysis}

Bulked segregant analysis (BSA) was used in conjunction with SSR analysis [18] to find markers linked to genes of physiological traits under drought stress. Tolerant and sensitive bulks were prepared from RILs ( $\mathrm{F}_{4}$ generation) individuals by pooling aliquots, containing equivalent amounts of total DNA, approximately, $50 \mathrm{ng} / \mu \mathrm{l}$ from each of ten sensitive and ten tolerant RILs plants selected, based on phenotypic assessments. SSR primers were tested and screened on parents and two bulk DNA samples, based on polymorphic patterns of primer combinations, not only among parental genotypes, but also between the pair of the bulk DNA. Based on the evaluations of DNA bulks, individual RILs plants were analyzed with co-segregating primers to confirm SSR markers linkage to the physiological traits as an indicator for drought tolerance genes.

\section{Data and linkage analysis}

Map Manager QTX Version 0.22 software [17] was used to perform composite interval mapping (CIM) [33] and to evaluate marker intervals putatively associated with trait phenotypes. Linkage was detected when a log of the likelihood ratio (LOD) threshold was 3.0 and maximum distance was $50 \mathrm{cM}$. The Kosambi's mapping function was used. Genetic loci with the most significant effect for each QTL were assembled into multiple regression models, using PROC REG of SAS version 9.1 software packages [25], to determine the total amount of the phenotypic variation explained [19].

\section{RESULTS}

\section{SSR analysis}

Out of 400 different SSR markers used in this study, only 120 primer pairs generated polymorphisms between the parents. Each of these markers was used to screen DNA bulks of the ten tolerant and the ten sensitive $\mathrm{F}_{4}$ families according to the physiological traits. Twelve SSR markers were, only, amplified polymorphic bands for leaf 
chlorophyll content (Table 1). Nine SSR markers were dominant markers (Xgwm617, Wmc326, Xgwm334, Barc3, Barc64, Barc122, Barc123, Barc571 and Barc170). The SSR primers Xgwm334 and Barc571 generated one polymorphic fragment at 125 and 110 bp which was present only in the sensitive bulk and Yecora Rojo (sensitive parent) and was missing in the tolerant bulk and Pavon76 (tolerant parent). However, the other dominant SSR markers generated one polymorphic fragment, which was present only in the tolerant bulk and Pavon76 (tolerant parent) and was missing in sensitive bulk and Yecora Rojo (sensitive parent). Three SSR markers were co-dominant markers (Wmc93, Barc7 and Barc176). A typical amplification pattern generated by Wmc93 was shown in Fig. 1. Among the $27 \mathrm{~F}_{4}$ lines, nine had profiles of Pavon76, two of Yecora Rojo, and sixteen were heterozygotes (Fig. 1). The Wmc93 allele from the tolerant parent was larger than from the sensitive parent. This locus was inherited in a Mendelian co-dominant manner. There were clear co-segregations between the amplification of the larger $\mathrm{Wmc} 93$ allele and the $\mathrm{F}_{4}$ lines showing the tolerant phenotypes. In the homozygous sensitive $\mathrm{F}_{4}$ lines, only the smaller Wmc93 allele was amplified. In a proportion of tolerant $\mathrm{F}_{4}$ lines, both the larger and the smaller alleles were amplified, these lines were presumably heterozygous. The co-dominant microsatellite marker Wmc93 was able to identify the heterozygotes, and would serve as an important tool to rapidly transfer the drought tolerance genes into other wheat cultivars. The co-dominant microsatellite marker Wmc93 was able to identify the

Table 1

Genetic characteristics of QTL related to chlorophyll content $(\mathrm{CH})$ and flag leaf senescence (FLS) traits as indicator of drought tolerance in the $150 \mathrm{~F}_{4}$ families derived from Pavon $76 \times$ Yecora Rojo

\begin{tabular}{|c|l|c|r|r|r|r|c|}
\hline Trait & \multicolumn{1}{|c|}{$\begin{array}{c}\text { Primers } \\
\text { name }\end{array}$} & Locus & $\begin{array}{c}\text { QTL } \\
\text { (CM) }\end{array}$ & LOD & $\begin{array}{c}\mathrm{R}^{2} \\
(\%)\end{array}$ & $\begin{array}{c}\text { P } \\
\text { value }\end{array}$ & $\begin{array}{c}\text { Additive } \\
\text { effect }\end{array}$ \\
\hline \multirow{4}{*}{ CH } & Xgwm617 & 6A & 15.5 & 16.4 & 11 & 0.0001 & 0.99 \\
\cline { 2 - 8 } & Xgwm334 & 6A & 18.4 & 8.9 & 23 & 0.0001 & 1.65 \\
\cline { 2 - 8 } & Wmc93 & 3A & 24.7 & 10.9 & 33 & 0.0001 & 1.66 \\
\cline { 2 - 8 } & Wmc326 & 3B & 22.6 & 11.5 & 42 & 0.0001 & 1.95 \\
\cline { 2 - 8 } & Barc17 & 1A & 19.3 & 14.6 & 22 & 0.0001 & 1.10 \\
\cline { 2 - 8 } & Barc170 & 4A & 12.5 & 18.6 & 33 & 0.0001 & 1.69 \\
\cline { 2 - 8 } & Barc122 & 5A & 18.4 & 12.5 & 27 & 0.0001 & 1.59 \\
\cline { 2 - 8 } & Barc3 & 6A & 18.6 & 12.8 & 14 & 0.0001 & 1.05 \\
\cline { 2 - 8 } & Barc64 & 7A & 20.9 & 13.7 & 14 & 0.0001 & 1.01 \\
\cline { 2 - 8 } & Barc571 & 3D & 15.4 & 23.7 & 17 & 0.0001 & 0.92 \\
\cline { 2 - 8 } & Barc123 & 6D & 13.4 & 18.2 & 27 & 0.0001 & 1.48 \\
\cline { 2 - 8 } & Barc76 & 7D & 16.8 & 17.6 & 22 & 0.0001 & 1.10 \\
\hline FLS & Wmc93 & 1A & 23.3 & 6.8 & 6 & 0.0001 & -0.08 \\
\cline { 2 - 8 } & Wmc105 & 6B & 16.8 & 11.7 & 13 & 0.0001 & -0.11 \\
\cline { 2 - 8 } & Wmc167 & 2D & 18.1 & 9.8 & 12 & 0.0001 & -0.12 \\
\cline { 2 - 8 } & Barc141 & 5A & 17.4 & 12.7 & 27 & 0.0001 & -0.41 \\
\cline { 2 - 8 } & Barc194 & 1B & 13.9 & 15.7 & 21 & 0.0001 & -0.13 \\
\hline
\end{tabular}




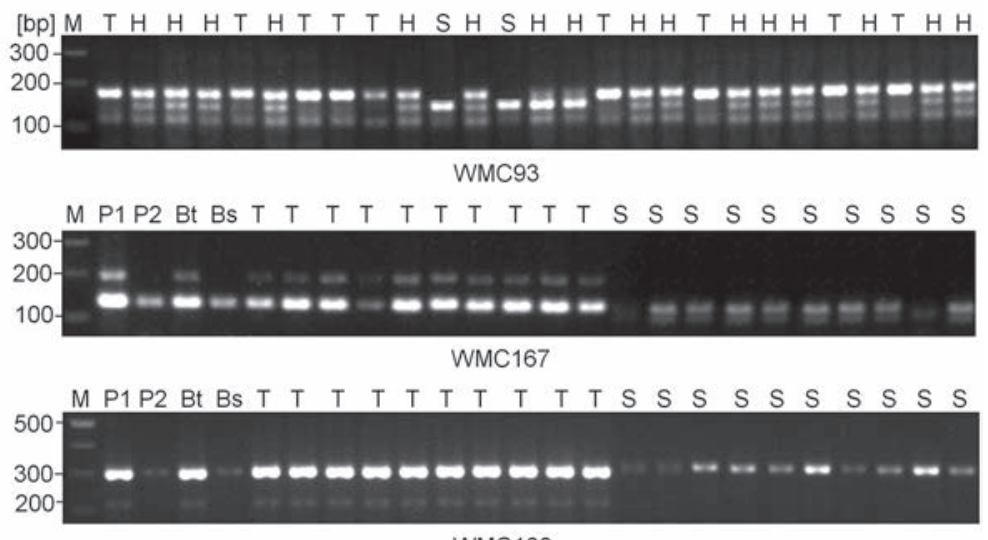

Fig. 1. Selective genotyping of $\mathrm{F}_{4}$ families of Pavon76 $\times$ Yecora Rojo wheat hybrids with Wmc93, Wmc167 and Wmc168 markers for leaf chlorophyll content, flag leaf senescence and cell membrane stability traits, respectively. $\mathrm{M}$ - molecular weight, P1 - Pavon76, P2 - Yecora Rojo, Bt - tolerant bulk, $\mathrm{Bs}$ - sensitive bulk, $\mathrm{T}-\mathrm{F}_{4}$ tolerant lines, $\mathrm{S}-\mathrm{F}_{4}$ sensitive lines, $\mathrm{H}$ - heterozygote

heterozygotes. The segregation ratio was 1 (37 tolerant homozygotes): 2 (72 heterozygotes): 1 (35 sensitive homozygotes) in the genotyping $\mathrm{F}_{4}$ lines. The ratio fitted the expected Mendalian ratio, 1: $2: 1\left(\chi^{2}=0.45\right)$.

Five SSR markers (Wmc93, Wmc105, Wmc167, Barc194 and Barc141) have been identified for flag leaf senescence (Table 1). The amplification profiles of the SSR primer pairs were characterized by the $\mathrm{F}_{4}$ families and their parents. The SSR primers Wmc93, Wmc105, Wmc167, Barc194 and Barc141 generated one polymorphic fragment at 190, 320, 200, 170 and $270 \mathrm{bp}$, respectively, which was present only in the tolerant bulk and Pavon76 (tolerant parent) and was missing in the sensitive bulk and Yecora Rojo (sensitive parent) (Fig. 1).

Ten SSR markers were linked to cell membrane stability (Table 2). Three SSR markers were co-dominant (Barc12, Barc137 and Barc80). The other seven SSR markers were dominant markers Wmc27, Wmc168 and wmc216, which were present only in the tolerant bulk and Pavon76 (tolerant parent) and were missing in sensitive bulk and Yecora Rojo (sensitive parent) (Fig. 1).

\section{QTL analysis}

Multiple regression analysis was carried out to confirm the association between the detected SSR markers and the physiological traits as an indicator for drought tolerance genes in all $150 \mathrm{~F}_{4}$ families. The results revealed a highly significant regression between the twelve SSR markers and leaf chlorophyll content of the phenotypes of $\mathrm{F}_{4}$ families (Table 1). The explained variances were ranged from 11 to $42 \%$ (Table 1). Also, the Wmc93, Wmc105, Wmc167, Barc194 and Barc141 markers were signifi- 
Table 2

Genetic characteristics of QTL related to cell membrane stability (CMS) trait as indicator of drought tolerance in the $150 \mathrm{~F}_{4}$ families derived from Pavon $76 \times$ Yecora Rojo

\begin{tabular}{|l|c|c|c|c|c|c|}
\hline Primers name & Locus & $\begin{array}{c}\text { QTL } \\
(\mathrm{CM})\end{array}$ & LOD & $\begin{array}{c}\mathrm{R}^{2} \\
(5)\end{array}$ & $\begin{array}{c}\text { P } \\
\text { value }\end{array}$ & $\begin{array}{c}\text { Additive } \\
\text { effect }\end{array}$ \\
\hline Barc12 & 3A & 23.8 & 9.7 & 7 & 0.0001 & 0.05 \\
\hline Barc115 & 5A & 16.5 & 12.9 & 14 & 0.0001 & 0.08 \\
\hline Barc10 & 5A & 19.8 & 13.2 & 17 & 0.0001 & 0.08 \\
\hline Wmc168 & 7A & 19.2 & 11.9 & 26 & 0.0001 & 0.09 \\
\hline Wmc216 & 1B & 14.3 & 15.0 & 10 & 0.0001 & 0.06 \\
\hline Barc137 & 1B & 22.5 & 9.5 & 8 & 0.0001 & 0.05 \\
\hline Barc80 & 1B & 18.2 & 15.8 & 15 & 0.0001 & 0.06 \\
\hline Barc188 & 1B & 20.5 & 9.4 & 10 & 0.0001 & 0.07 \\
\hline Barc81 & 1B & 16.2 & 15.3 & 15 & 0.0001 & 0.07 \\
\hline Wmc27 & 2B & 25.5 & 8.1 & 24 & 0.0001 & 0.10 \\
\hline Barc147 & 3B & 22.9 & 12.4 & 7 & 0.0001 & 0.06 \\
\hline Barc164 & 3B & 21.9 & 8.3 & 13 & 0.0001 & 0.08 \\
\hline
\end{tabular}

cantly $(\mathrm{P}<0.01)$ associated with the flag leaf senescence and explained $6,13,12$, 21 and $27 \%$ of the variation, respectively (Table 1). In addition, ten SSR markers (Table 2 ) were significantly $(\mathrm{P}<0.01)$ associated with the cell membrane stability and the explained variances were ranged from 7 to $26 \%$ (Table 2). This indicates that the SSR markers were associated with the physiological traits under investigations as an indicator for drought tolerance genes.

The linkage relationship between the twenty-eight SSR markers and the physiological traits as an indicator for drought tolerance genes were estimated, using the $\mathrm{F}_{4}$ families, deriving from the cross, Pavon $76 \times$ Yecora Rojo. The genetic distance between the twenty eight SSR markers and drought tolerance genes were ranged from 12.5 to $25.5 \mathrm{~cm}$, with range of LOD scores from 6.8 to 23.7 (Tables 1 and 2). Therefore, these SSR markers were linked to the quantitative trait loci (QTL) for the physiological traits under investigation as an indicator for drought tolerance genes.

The results in the present investigation indicated that all of the QTLs using SSR markers for leaf chlorophyll content, and cell membrane stability had a positive additive effect indicating contribution of alleles increasing the chlorophyll content, and cell membrane stability by the tolerant parent 'Pavon76' (Tables 1 and 2). Positive additive effect of the QTL, on chromosomes 1A, 3A, 4A, 5A, 6A, 7A, 1B, 2B, 3B, 6B, 2D, 3D, 6D and 7D using SSR markers, indicates contribution of QTL alleles in these loci from the tolerant parent, 'Pavon76'. In addition, the positive additive effects indicates the relative importance of additive gene effects in controlling leaf chlorophyll content cell, and membrane stability as an indicator for drought tolerance in $\mathrm{F}_{4}$ families. The negative additive effects for flag leaf senescence indicate that the sensitive parent 'Yecora Rojo' alleles are in the direction of increasing the trait. 


\section{DISCUSSION}

Identification of associated molecular markers at a major locus contributing to waterstress tolerance would be useful for the indirect selection of wheat plants for waterstress tolerance [31]. However, identifying molecular markers associated with important genes or traits in most instances requires screening a relatively large number of individuals in the population. Bulked segregant analysis (BSA) was originally developed to overcome such difficulty since comparing bulk samples is easier than evaluating many individuals in different populations $[1,3]$. BSA was first reported by Michelmore et al. [18] to identify RAPD markers tightly linked to genes for resistance to lettuce downy mildew. In this study, mapping quantitative trait loci for leaf chlorophyll content, flag leaf senescence, and cell membrane stability traits as indicator for drought tolerance gene in wheat under drought stress are described in the population of wheat hybrids (Pavon76 $\times$ Yecora Rojo) using SSR markers. Using bulked segregant analysis (BSA), we were able to identify twenty-eight SSR markers linked to the three physiological traits (leaf chlorophyll content, flag leaf senescence, and cell membrane stability traits), as indicator for drought tolerance gene in wheat.

In the present study, the twenty-eight SSR markers were assigned to chromosomes $1 \mathrm{~A}, 3 \mathrm{~A}, 4 \mathrm{~A}, 5 \mathrm{~A}, 6 \mathrm{~A}, 7 \mathrm{~A}, 1 \mathrm{~B}, 2 \mathrm{~B}, 3 \mathrm{~B}, 6 \mathrm{~B}, 2 \mathrm{D}, 3 \mathrm{D}, 6 \mathrm{D}$ and $7 \mathrm{D}$ in agreement with previous report [15, 22, 27]. Homoeologous groups of chromosomes 2, 3, 5 and 7 of wheat contain a number of genes that are important for tolerance to abiotic stress [9, 12]. Previously, Cao et al. [6] detected seven QTLs for chlorophyll content on chromosomes 2B, 4A, 5B, 6A, 7A, and 7D under nitrogen $(\mathrm{N})$ sufficient environment, while nine QTLs were identified for chlorophyll content on chromosomes 2D, 3A, $4 \mathrm{~B}, 5 \mathrm{~B}$, and $6 \mathrm{~A}$ when wheat seedlings are grown under $\mathrm{N}$ deficient environment. Yang et al. [32] reported that four additive QTLs controlling chlorophyll content under both rainfed and well-watered conditions were mapped on chromosomes $1 \mathrm{~A}$, $5 \mathrm{~A}$, and 7A at grain filling stage. The QTL for flag leaf senescence was discovered on the chromosomes 2B and 2D and the QTLs identified on chromosome 2D associated with better performance under drought stress [30]. SSR markers Wmc9, Wmc596, Wmc603 and Barc108 were weakly but significantly associated with cell membrane stability after water stress [7]. Żur et al. [34] found significant $(p<0.01)$ association with markers localized on chromosome 4A and 5A for unstressed plants and on chromosomes 3A, 3B and 5B for low temperature treated plants. Recently, Barakat et al. [3] reported that quantitative trait locus for flag leaf senescence was associated with 1 RAPD marker, 4 ISSR markers, and 1 SSR marker and were located on the 2D chromosome. Our results also show that the allelic contribution to the physiological traits QTLs came from both parents. A negative additive effect indicates that the source of the allele for flag leaf senescence was Yecora Rojo. On the other hand, the positive additive effects indicates the relative importance of additive gene effects in controlling the leaf chlorophyll content, and cell membrane stability as an indicator for drought tolerance in $\mathrm{F}_{4}$ families.

QTLs for leaf chlorophyll content, flag leaf senescence, and cell membrane stability traits in wheat under water-stressed conditions were associated with the twenty- 
eight SSR markers and explained from 6 to $42 \%$ of the phenotypic variation for three physiological traits. These markers should be useful for marker-assisted selection. Molecular markers that are closely linked with target alleles present a useful tool in plant breeding since they can help to detect the tolerant genes of interest without the need of carrying out field evaluation. Also, it allows screening large number of breeding materials at early growth stages and in a short time.

\section{ACKNOWLEDGEMENTS}

The authors express their appreciation to the Deanship of Scientific Research at King Saud University for funding the work by the research group project No. RGPVPP-161.

\section{REFERENCES}

1. Altinkut, A., Gozukirmizi, N. (2003) Search for microsatellite markers associated with water-stress tolerance in wheat through bulked segregant analysis. Mol. Biotechnol. 23, 97-106.

2. Barakat, M. N., Al-Doss, A. A., Moustafa, K. A., Ahmed, E. I., Elshafei, A. A. (2010) Morphological and molecular characterization of Saudi wheat genotypes under drought stress. J. Food Agricult. \& Environ. 8, 220-228.

3. Barakat, M. N., Wahba, L. E., Milad, S. I. (2013) Molecular mapping of QTLs for wheat flag leaf senescence under water-stress. Biol. Plant. 57, 79-84.

4. Baum, M., Grando, S., Backes, G., Jahoor A., Sabbagh, A., Ceccarelli, S. (2003) QTLs for agronomic traits in the Mediterranean environment identified in recombinant inbred lines of the cross 'Arta' $\times$ H. spontaneum 41-1. Theor. Appl. Genet. 107, 1215-1225.

5. Blum, A., Ebercon, A. (1981) Cell membrane stability as a measure of drought and heat tolerance in wheat. Crop Sci. 21, 43-47.

6. Cao, W. D., Jia, J. Z., Jin, J. Y. (2004) Identification and interaction analysis of QTL for chlorophyll content in wheat seedlings. Plant Nutr. Ferti. Sci. 10, 473-478.

7. Ciucă, M., Petcu, E. (2009) SSR markers associated with membrane stability in wheat (Triticum aestivum L.). Rom. Agricult. Res. 26, 21-24.

8. Courtois, B., McLaren, G., Sinha, P. K., Prasad, K., Yadav, R., Shen, L. (2000) Mapping QTLs associated with drought avoidance in upland rice. Mol. Breeding 6, 55-66.

9. Dubcovsky, J., Luo, M. C., Dvorák, J. (1995) Linkage relationships among stress-induced genes in wheat. Theor. Appl. Genet. 91, 795-801.

10. Dwyer, L. M., Tollenaar M., Houwing, L. (1991) A nondestructive method to monitor leaf greenness in cron. Can. J. Plant Sci. 71, 505-509.

11. Elshafei, A. A., Saleh, M., Al-Doss, A. A., Moustafa, K. A., Al-Qurainy F. H., Barakat, M. N. (2013) Identification of new SRAP markers linked to leaf chlorophyll content, flag leaf senescence and cell membrane stability traits in wheat under water-stressed condition. Aust. J. Crop Sci. 7, 887-893.

12. Golabadi, M., Arzani, A., Maibody, S. M., Tabatabaei B. S., Mohammadi, S. A. (2011) Identification of microsatellite markers linked with yield components under drought stress at terminal growth stages in durum heat. Euphytica 177, 207-221.

13. Grando, S., Baum, M., Ceccarelli, S., Goodchild, A., El-Haramein., F. J, Backes, G. (2005) QTLs for straw quality characteristics identified in recombinant inbred lines of a Hordeum vulgare $\times H$. spontaneum cross in a Mediterranean environment. Theor. Appli. Genet. 110, 688-695.

14. Guo, P., Baum, M., Varshney, R. K., Graner, A., Grando, S., Ceccarelli, S. (2008) QTLs for chlorophyll and chlorophyll fluorescence parameters in barley under post-flowering drought. Euphytica 163, 203-214. 
15. Gupta, P., Balyan, H., Edwards, K., Isaac, P., Korzun, V., Röder, M., Leroy, P. (2002) Genetic mapping of 66 new microsatellite (SSR) loci in bread wheat. Theor. Appl. Genet. 105, 413-422.

16. McWilliam, J. (1989) The dimensions of drought. In: Baker, F. (ed.) Drought Resistance in Cereals. CAB International, Wallingford, UK, pp. 1-11.

17. Meer, J. M., Robert, H. C., Kenneth, F. M. (2002) Map Manager version 0.22. http://manager.roswellpark.org/mmQTX.html.

18. Michelmore, R. W., Paran, I., Kesseli, R. V. (1991) Identification of markers linked to disease-resistance genes by bulked segregant analysis: A rapid method to detect markers in specific genomic regions by using segregating populations. Proc. Natl. Acad. Sci. USA 88, 9828-9832.

19. Nelson, J. C. (1997) QGENE: software for marker-based genomic analysis and breeding. Mol. Breed 3, 239-245.

20. Peng, S., Garcia, F. V., Laza, R. C., Cassman, K. G. (1993) Adjust for specific leaf weight improves chlorophyll meter's estimates of rice leaf nitrogen concentration. Agron. J. 85, 987-990.

21. Quarrie, S., Dodig, D., Pekiç, S., Kirby, J., Kobiljski, B. (2003) Prospects for marker-assisted selection of improved drought responses in wheat. Bul. J. Plant. Physiol. Special Issue (Proc. Eur. Workshop Environ. Stress and Sustainable Agricult., Varna, Bulgaria) pp. 83-95.

22. Röder, M. S., Korzun, V., Wendehake, K., Plaschke, J., Tixier, M. H., Leroy, P., Ganal, M. W. (1998) A microsatellite map of wheat. Genetics 149, 2007-2023.

23. Saghai-Maroof, M. A., Soliman, K. M., Jorgensen, R. A., Allard, R. W. (1984) Ribosomal DNA spacer-length polymorphisms in barley: Mendelian inheritance, chromosomal location, and population dynamics. PNAS 81, 8014-8018.

24. Saleh, M. S., Al-Doss, A. A., Elshafei, A. A., Moustafa, K. A., Al-Qurainy, F. H., Barakat, M. N. (2013) Identification of new TRAP markers linked to chlorophyll content, leaf senescence, and cell membrane stability in water-stressed wheat. Biol. Plant. 58, 64-70.

25. SAS. 2007. SAS/STAT. Guide for personal computers. Version 9 ed. SAS end. SAS Institute, Cary, NC, USA.

26. Shen, L., Courtois, B., McNally, K. L., Robin, S., Li, Z. (2001) Evaluation of near-isogenic lines of rice introgressed with QTLs for root depth through marker-aided selection. Theor. Appl. Genet. 103, 75-83.

27. Song, Q., Shi, J., Singh, S., Fickus, E., Costa, J., Lewis, J., Cregan, P. (2005) Development and mapping of microsatellite (SSR) markers in wheat. Theor. Appl. Genet. 110, 550-560.

28. Takeda, S., Matsuoka, M. (2008) Genetic approaches to crop improvement: responding to environmental and population changes. Nat. Rev. Genet. 9, 444-457.

29. Tuberosa, R., Salvi, S. (2006) "Genomics-based approaches to improve drought tolerance of crops." Trends Plant Sci. 11, 405-412.

30. Verma, V., Foulkes, M., Worland, A., Sylvester-Bradley, R., Caligari, P., Snape, J. (2004) Mapping quantitative trait loci for flag leaf senescence as a yield determinant in winter wheat under optimal and drought-stressed environments. Euphytica 135, 255-263.

31. Visser, B. (1994) Technical aspects of drought tolerance. Biotechnol. Dev. Monitor 18, 5.

32. Yang, D. L., Jing, R. L., Chang, X. P., Li, W. (2007) Quantitative trait loci mapping for chlorophyll fluorescence and associated traits in wheat (Triticum aestivum). J. Integr. Plant Biol. 49, 646-654.

33. Zeng, Z. B. (1994) Precision mapping of quantitative trait loci. Genetics 136, 1457-1468.

34. Żur, I., Krzewska, M., Dubas, E., Gołębiowska-Pikania, G., Janowiak, F., Stojałowski, S. (2012) Molecular mapping of loci associated with abscisic acid accumulation in triticale $(\times$ Triticosecale Wittm.) anthers in response to low temperature stress inducing androgenic development. Plant Growth Reg. 68, 483-492. 